\title{
Tiro-aztarnen identifikazioa, auzitegi-laborategien erronka
}

\author{
Nora Unceta*, Nagore Grijalba, Sandra Benito, Zuriñe Abrego, \\ Alicia Sánchez, M. Aránzazu Goicolea, Alberto Gomez, \\ Asier Vallejo eta Ramón J. Barrio \\ Kimika Analitikoa Saila, Farmazia Fakultatea (UPV/EHU) \\ *nora.unceta@ehu.eus
}

DOI: 10.1387/ekaia.14556

Onartua: 2015-07-17

Laburpena: Azken urteotan, su-armen erabilera nabarmen handitu da gure gizartean eta horrek tiro egin ondoren sortutako partikulen analisirako metodologia berriak garatzea ekarri du. Krimenaren gertalekuan tiro-aztarnak (gunshot residue, GSR) osatzen dituzten konposatuen detekzioak eta identifikazioak su-armen erabileraren ebidentzia fidagarria eskaintzen dute. Tiro-aztarnak erretako eta erre gabeko partikulen multzoa dira, munizioa erretzen denean sortutakoak eta su-armak berak, jaurtigaiak eta kartutxoak askatutako konposatuez osatuak. Tiro egin ostean, partikulak tiroa gertatu den tokiaren inguruan jalkitzen dira, baina, batez ere, tiratzailearen gorputzean (eskuak, sudurra eta ilea) eta arropetan. Gaur egun, GSR partikulen ohiko analisia konposatu ez-organikoen identifikazioan oinarritzen da. Konposatu organikoen azterketak (organic gunshot residues, OGSR) lagin baten froga-balioa indartu dezake. Hala ere, gutxi dira OGSRen dudarik gabeko identifikaziorako guztiz sentikorrak diren metodoak. Lan honetan, beraz, tiro-aztarnen lagin-biltzea eta analisirako teknika aipagarrienak laburbildu eta berrikusten dira.

Hitz-gakoak: Auzitegiko zientzia, tiro-aztarna ez-organikoak (IGSR), tiro aztarna organikoak (OGSR), lagin-biltzea, metodo analitikoak.

\begin{abstract}
In the last years, the use of firearms has increased considerably in our society which has raised the development of new analytical methodologies in order to detect the particles formed during shooting. The detection and identification of compounds consistent with gunshot residues (GSR) in a crime scene provides forensic evidence of the use of firearms. These particles are a set of burned and unburned particles formed as a result of the combustion process of ammunition and contain components expelled from the firearm itself, the projectile and the cartridge case. After the discharge, particles are deposited on all surfaces in the vicinity where the shot has taken place but mainly in shooter's body (hands, nose and hair) and clothing. Currently, conventional analysis of GRS is focused on inorganic components. The study of organic components may strengthen the probative value of a sample. However, only a few studies propose analytical methods sensitive enough to identify OGSR. The cur-
\end{abstract}


Nora Unceta, Nagore Grijalba, Sandra Benito, Zuriñe Abrego, Alicia Sánchez, M. Aránzazu Goicolea, Alberto Gomez, Asier Vallejo, Ramón J. Barrio

rent manuscript reviews the different approaches present in the literature for determining the presence of gunshot residues (GSR) including sample collection and analysis by different analytical techniques.

Keywords: Forensic science, inorganic gunshot residues (IGSR), organic gunshot residues (OGSR), sample collection, analytical methods.

\section{SARRERA}

Tiro-aztarnak (gunshot residue, GSR) munizioaren errekuntza prozesuaren ondorioz sortzen den partikula sorta da [1,2]. Partikula horiek krimenaren gertalekuan aurkitzea su-armaren bat erabili izanaren ebidentzia fisiko eta kimikoa da. Auzitegi-analisiaren ikuspuntutik, ustez su-armaz tiro egin duen pertsona bat identifikatu ahal izateko, ezinbestekoa da gorputzean, batez ere eskuetan eta arropan, atxiki diren tiro-aztarnak ziurtasun osoz identifikatzea. Gainera, partikula horien sakabanaketaren arabera hilketa ala suizidioa izan den bereiz daiteke [3].

Tiro-aztarnak arma kliskatu bezain azkar sortzen dira. Hasarazlea munizioaren behe aldean kokatzen den kapsula batean aurkitzen da eta osagai hauek ditu: lehergaiak, erreakzio kimikoa oxigenoz hornitzeko eragile oxidatzaileak, sugarraren bolumena eta tenperatura handitzeko erregaiak eta lehergaiaren pizketan laguntzeko urratzaileak. Armaren kolpekariak hasarazlearen tapa jotzen duenean su hartzen du hark eta bala-zorro barneko tenperatura eta presioa areagotu egiten dira bat-batean $1600{ }^{\circ} \mathrm{C}$-ko tenperaturak gainditzeraino. Horrek sutu egiten du bolbora eta, ondorioz, sortzen diren gasen bolumen handia dela eta, presioa areagotu eta bala armaren kanoitik kanporatzen da. Bolboran eta hasarazlean aurkitzen diren substantziak muturreko tenperatura eta presioen baldintzapean aurkitzen dira, eta jarraian bat-bateko hoztea jasaten dutenez, solidotu egiten dira eta tiroaztarnak osatzen dituzten partikulak sortzen dituzte (1go irudia) [4,5].
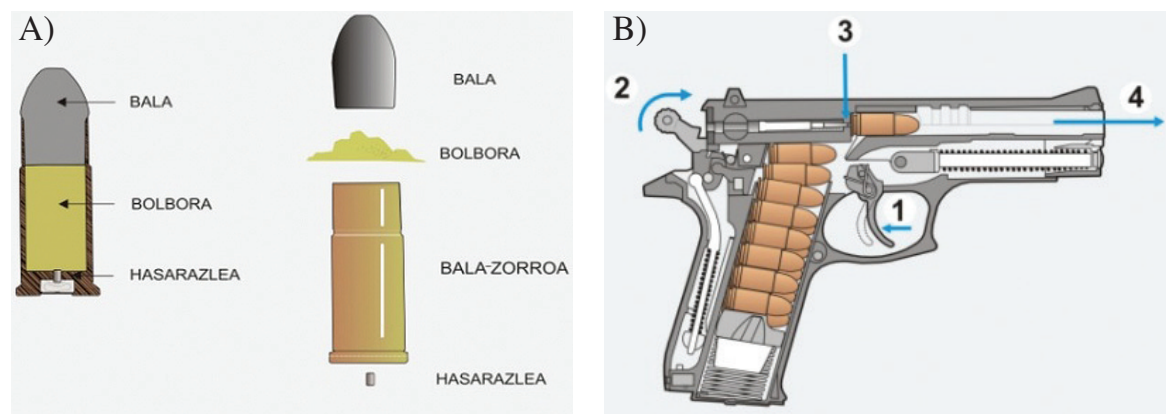

1. irudia. A) Munizioaren osagaiak. B) Balaren kanporatze prozesua: 1. Arma kliskatu egiten da; 2. Kolpekariak hasarazlearen tapa kolpatzen du; 3. Hasarazleak su hartu eta bolbora erretzen du; 4. Bala armaren kanoitik ateratzen da. 
Tiro-aztarnen identifikazioa, auzitegi-laborategien erronka

Tiro-aztarnak prozesu horretan erretako eta erre gabeko partikulek sortzen dituzte. Nahiz eta haien jatorri nagusia bolbora eta hasarazlea izan, su-armatik beretik, balatik eta bala-zorrotik ere partikulak askatu daitezke. Hori dela eta, partikula hauek konposizio organiko nahiz ez-organikoa izan dezakete [2].

Gaur egun, tiro-aztarnen ohiko analisia konposatu ez-organikoen identifikazioan oinarritzen da. Konposatu ez-organiko gehienen iturria hasarazlea da, hau da: lehergaia, eragile oxidatzailea eta erregaia. Lehergai erabiliena berun estifnatoa (beruna 2,4,6-trinitroerresorzinatoa) da, eta hari, askotan, tetrazenoa gehitzen zaio nahasketa ahalik eta sentikorren izan dadin. Eragile oxidatzaile gisa bario nitratoa, berun nitratoa eta bario edo berun peroxidoak erabiltzen dira, eta erregai gisa, aldiz, antimonio sulfuroa [6,7].

Konposizio ez-organikoan oinarrituz, 2008. Urtean European Network of Forensic Science Institute (ENFSI) delakoak tiro-aztarnen analisirako gida plazaratu zuen, eta urte batzuk geroago American Society for Testing and Materials (ASTM) erakundeak ontzat jo zuen irizpide hori. Haren esanetan, tiro-aztarnak 0.5 eta $5.0 \mu \mathrm{m}$ tarteko diametroa duten partikula esferikoak izan behar dira. Partikula horiek bi taldetan sailkatzen dituzte haien konposizioaren arabera: partikula «bereizgarriak» (characteristic) eta «bateragarriak» (consistent) (1. Taula). Partikula bereizgarriak beruna $(\mathrm{Pb})$, antimonioa $(\mathrm{Sb})$ eta barioa $(\mathrm{Ba})$ daukaten partikulak dira, eta horiek tiro egin ostean bakarrik sor daitezkeela egiaztatu daiteke. Partikula bateragarrien konposizioa anitzagoa da, baina nahiz eta su-armaz tiro egitean sor daitezkeen, haien jatorria beste bat izan daiteke $[8,9]$.

1. Taula. Tiro-aztarna ez-organikoen sailkapena (ENFSI)[8].

\begin{tabular}{cc}
\hline Bereizgarriak & Bateragarriak \\
\hline & $\mathrm{Ba}, \mathrm{Ca}$ eta $\mathrm{Si}$ \\
$\mathrm{Sb}$ eta $\mathrm{Ba}$ \\
$\mathrm{Pb}$ eta $\mathrm{Sb}$ \\
$\mathrm{Pb}, \mathrm{Sb}$ eta $\mathrm{Ba}^{*}$ & $\mathrm{Ba}$ eta $\mathrm{Al}$ \\
& $\mathrm{Pb}$ eta $\mathrm{Ba}$ \\
$\mathrm{Pb}$ \\
$\mathrm{Ba}$ \\
$\mathrm{Sb}$
\end{tabular}

* Partikula hauek $\mathrm{Si}, \mathrm{Ca}, \mathrm{Al}, \mathrm{Cu}, \mathrm{Fe}, \mathrm{S}, \mathrm{Zn}, \mathrm{Ni}, \mathrm{K}, \mathrm{Cl}$ eta $\mathrm{Sn}$ eduki dezakete.

Hala ere, azken urteotan, irizpide hori zalantzan jartzen duten zenbait ikerketa plazaratu dira. Alde batetik, zenbait ikertzailek zalantzan jarri dute tiro-aztarnen partikulen esferikotasuna [10]; bestetik, eztabaida sortu da partikula bereizgarrien konposizioaren esklusibotasunari buruz, $\mathrm{Pb}-\mathrm{Ba}-\mathrm{Sb}$ 
Nora Unceta, Nagore Grijalba, Sandra Benito, Zuriñe Abrego, Alicia Sánchez, M. Aránzazu Goicolea, Alberto Gomez, Asier Vallejo, Ramón J. Barrio

konposizio elementala duten partikulak piroteknian eta balazta-pastillak egiten diharduten pertsonetan aurkitu baitira $[11,12]$.

Orain dela urte batzuk, tiro-eremuetan sortzen diren metal astunen maila altuen eraginpean sor daitezkeen osasun eta ingurumen arazoak saihesteko, «berunik gabeko» («lead-free») eta «metal astunik gabeko» («heavy metal free») munizioak merkaturatu ziren, eta azkeneko horietan ordezkatu egin zen hasarazleko beruna, barioa eta antimonioa estrontzioarekin, potasiodun oxidatzaileekin, diazodinitrofenolarekin edo kaltzio siliziuroarekin [13-15]. Munizio berdeak deritzen horiek, alabaina, ENFSIren irizpideetan oinarritutako zalantzarik gabeko tiro-aztarnen identifikazioa egitea galarazten dute. Azkeneko urteotan zenbait ikerlarik berunik gabeko munizioak erabiltzean sortzen diren partikulen analisi elementala burutu dute, eta ENFSIk berak ere partikulen konposizio bat proposatu du Alemaniako poliziak erabiltzen dituen munizioetan oinarrituz [8]. Tamalez, ikerketa horiek guztiek ez dute bat egiten munizio berdeak tiro egitean sortzen diren partikulen konposizio elementalari dagokionez, eta horrek munizio bakoitza kasuz kasu aztertzera behartzen du .

Arazo horren irtenbide bideragarriago bat munizio horiek erabiltzen direnean tiro-aztarnen konposatu ez-organiko zein organikoen identifikazioa egitea da. Konposatu organikoen erabilera munizioen garapenarekin batera hedatuz joan da. Antzina erabiltzen ziren lehenengo bolborak batez ere potasio nitratoaz (\%75), sulfuroaz (\%15) eta ikatzez (\%10) osatuta zeuden, eta formulazio horri bolbora beltza zeritzon. Egun, ordea, kerik gabeko bolborek bolbora beltza ordezkatu dute [3].

Kerik gabeko bolboren artean oinarri bakarrekoak (nitrozelulosa lehergai gisa daramatenak), bikoitzekoak (bai nitrozelulosa bai nitroglizerina daramatenak) eta hirukoitzekoak (aurreko bi konposatuez gain nitroguanidina duten bolborak) bereizten dira. Dena den, nitrozelulosa, nitroglizerina eta nitroguanidina ez dira kerik gabeko bolboren osagai bakarrak. Horietaz gain, besteak beste egonkortzaileak, plastifikatzaileak, distiraren inhibitzaileak, sentikortzaileak, hoztaileak, azaleraren labaingarriak, aglutinatzaileak eta higaduraren aurkako gehigarriak ere badaude [2,3]. Oro har, tiro-aztarnen konposatu organikoak hasarazlearen nahasketatik eta bolboratik eratzen dira batez ere. Hortaz, tiro-aztarnetan aurki daitezkeen konposatu organikoen zerrenda oso luzea da eta aldakorra izan daiteke, gainera, erabilitako munizioaren arabera ere.

\section{LAGIN-BILTZE TEKNIKAK}

Tiro egitean sor daitezkeen tiro-aztarnen kopurua zenbait faktoreren menpe dago; esate baterako: arma mota, antzinatasuna eta zaintze-baldintzak, tiroa gertatu ondoren igaro den denbora eta tiratzailearen lanbidea eta ohiturak. Hori horrela, ezinbestekoa da tiro aztarnen sakabanaketa nola gerta- 
Tiro-aztarnen identifikazioa, auzitegi-laborategien erronka

tzen den ondo ulertzea lagin-biltzea zuzena izan dadin eta zeharkako kutsatzerik gerta ez dadin, horrek zehaztasunik gabeko emaitzak eta ondorioak ekar ditzakeelako.

Esan bezala, pertsona batek su-armaz tiro egin duela egiaztatzeko, tiroaztarnen lagin-biltze puntu ohikoena arma eusten duen eskuaren erpurutik hatz erakuslera doan tartea da, hura baita partikulen iturburutik gertuen dagoen eremua. Gainera, nabarmendu beharra dago lehergaiek duten izaera lipofilikoa dela eta, gizakion larruazalean metatzeko joera handiagoa dutela [16].

Gaur egun, tiro aztarnen lagin-biltzea egiteko teknika erabilienak tape lifting eta swabbing delakoak dira. Tape lifting teknikan karbonozko zinta itsaskor batez estalita dagoen eta $12.7 \mathrm{~mm}$-ko diametroa duen euskarri metaliko borobil bat erabiltzen da, plastikozko kapsula baten barruan babestuta dagoena (2A. irudia) $[17,18]$.

Swabbing teknikan, aldiz, partikulak jasotzeko material absorbatzaile bat erabiltzen da [19]. Teknika horren baitan dispositiborik erabilienak kotoi-zotz edo isipuak dira, eta gehienetan beharrezkoa izaten da lagin-biltzearen aurretik dispositibo horiek disolbatzaile organikoarekin bustitzea (2B. irudia).
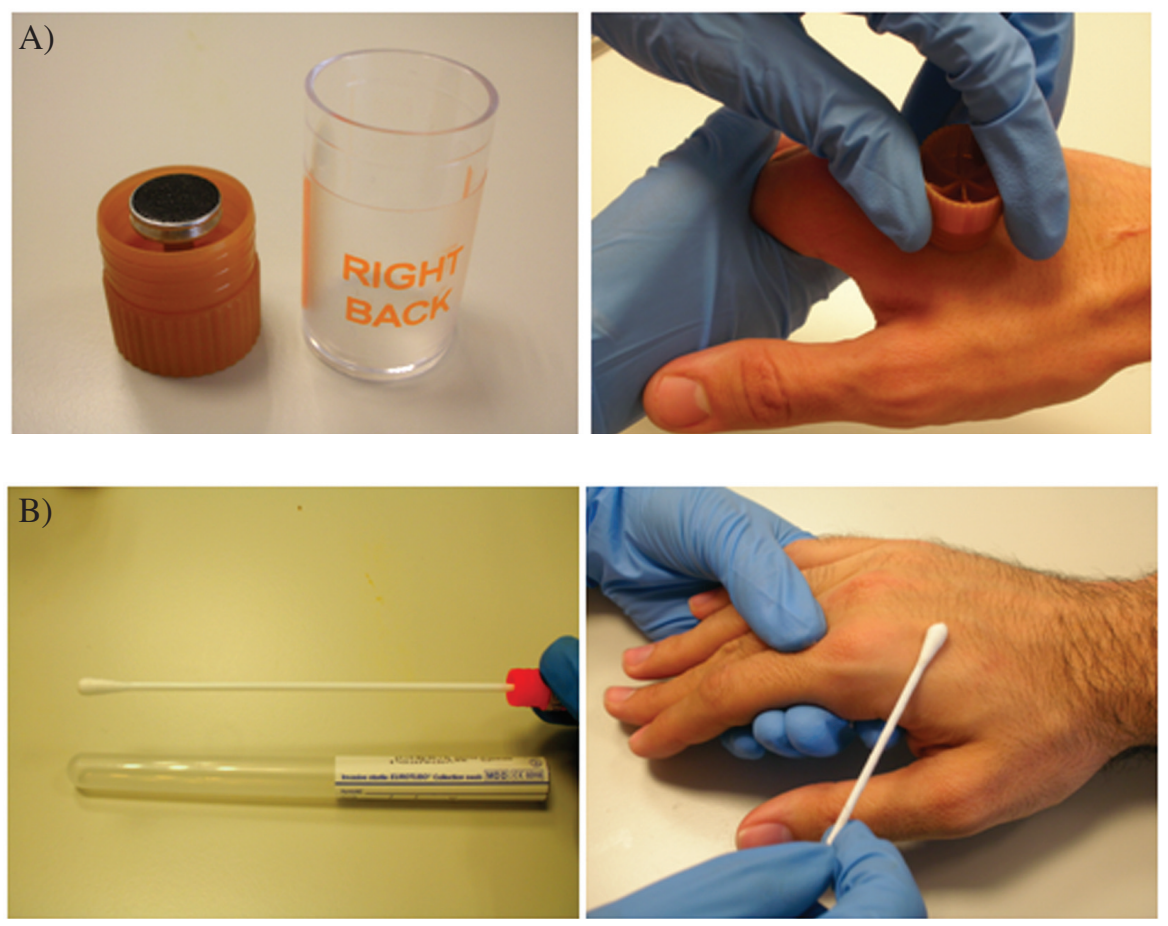

2. irudia. A) Tape lift bat eta haren erabilera tiro-aztarnen lagin-biltzean. B) Isipua eta haren erabilera tiro-aztarnen lagin-biltzean. 
Nora Unceta, Nagore Grijalba, Sandra Benito, Zuriñe Abrego, Alicia Sánchez, M. Aránzazu Goicolea, Alberto Gomez, Asier Vallejo, Ramón J. Barrio

\section{METODO ANALITIKOAK}

Krimen agertoki batean tiro-aztarnen presentzia baieztatzeko, lehendabizi, kolore aldaketan oinarritzen diren test kimikoak erabiltzen dira. Haietako batzuk partikuletan aurkitzen diren konposatu ez-organikoen detekzioan oinarritzen dira, Rhodizonatoaren testa, kasu. Beste batzuk, ordea, partikula organikoetan eragindako erreakzioetan oinarritzen dira; esate baterako: parafinaren testa, Griess-en testa, Griess-en test eraldatua edota S Alizarina Gorria (Alizarin Red S) testa [2].

Dena den, test kimiko horiek guztiek zenbait elementu edo talde funtzionalen analisi kualitatiboa egiteko aukera besterik ez dute ematen. Hortaz, tiro-aztarnen benetako konposizioa jakiteko, ezinbestekoa da teknika analitiko instrumentalak erabiltzea.

Nahiz eta asko ikertu den arlo bat izan, tiro-aztarnen zalantzarik gabeko identifikazioak buruhauste handiak sortzen ditu auzitegi-ikerlarien artean. Hori dela eta, gaur egun, auzitegiko ebidentzia fidagarriak lortu ahal izateko, nabarmena da partikula horien konposatu ez-organiko eta organikoen analisia burutzeko beharra.

\subsection{Tiro-aztarna ez-organikoen analisia}

Partikula ez-organikoen analisirako erabili izan diren teknika analitikoak aktibazio neutroniko bidezko analisia (NAA) [20], xurgapen atomikoko espektroskopia (AAS) [21,22], foto-luminiszentzia [23,24], akoplamendu induktibozko plasma-emisio atomikoko espektrometria (ICP-AES) [25], akoplamendu induktibozko plasma-masa espektrometria (ICPMS) [26,27], ekorketa bidezko mikroskopia elektronikoa (SEM) [28] eta teknika elektrokimikoak dira [29].

American Society for Testing and Materials (ASTM) eta European Network of Forensic Science Institutes (ENFSI) erakundeen arabera, erreferentziazko teknika eta baliagarritasun judiziala duen teknika bakarra $\mathrm{X}$ izpien energia-dispertsiboaren espektroskopiari akoplatutako ekorketa bidezko mikroskopia elektronikoa (SEM-EDX) da [8,9].

Ekorketa bidezko mikroskopia elektronikoan elementu baten edo elementu multzo baten gainean fokatzen den elektroi-sorta energetiko bat erabiltzen da. Elektroi-sorta primario horrek elementuaren gain eragiten duenean elektroiak kitzikatu egiten dira eta energia-maila altuago batera egiten dute salto. Elektroi horiek beren funtsezko egoerara bueltatzen direnean $\mathrm{X}$ izpiak igortzen dituzte. $\mathrm{X}$ izpi horiek ekorketa bidezko mikroskopio elektroniko batean jaso daitezke dimentsio bakarreko edo bi dimentsioko mapak sortzeko, zeinetan laginaren gainazalean dagoen elementuen banaketa ikus daitekeen. Beraz, teknika horrek informazioa eskaintzen du, aldi 
Tiro-aztarnen identifikazioa, auzitegi-laborategien erronka

berean, tiro-aztarnen partikulen morfologiari eta konposizio ez-organikoari buruz [7].

Halere, SEM-EDX teknikak baditu zenbait desabantaila tiro-aztarnen analisia egiteko erabiltzen denean. Esate baterako, beharrezkoa du partikula bakoitzaren banakako identifikazioa, eta horrek denbora luzea behar duenez, garestitu egiten da analisiaren kostua [30]. Izan ere, nahiz eta programa informatiko aurreratuak erabili, analisiak zenbait ordu (8 eta 10 ordu artean) iraun dezake laginaren zentimetro karratu bakoitzeko. Gainera, lagin-biltzean erabiltzen den karbonozko zinta itsaskorrean ager daitezkeen eskuko azal, ile edo bestelakoek 0.5-5.0 $\mu \mathrm{m}$-ko partikulak estali ditzakete eta haiek zuzen identifikatzea eragotzi dezakete, eta ondorioz negatibo faltsuak emateko aukera areagotu [16].

SEM-EDX teknikaren desabantaila horiek gainditzeko asmoz, Abrego eta lankideek metodo analitiko bat garatu dute tiro-aztarnen dudarik gabeko identifikazioa egiteko, laser bidezko ablazioa eta akoplamendu induktibozko plasma-masa espektrometria (LA-ICPMS) konbinatzen dituen teknikan oinarritzen dena. Metodo horrek ez du behar laginaren aurretratamendurik eta nabarmen murrizten du analisi-denbora (66 min) [31].

Laser bidezko ablazioan, pultsu laburreko eta energia handiko laser bat hermetikoki itxita dagoen gelaxka batean kokatzen den laginaren gainazalean fokatzen da. Horrek erauzi egiten ditu, laginaren gainazaletik, partikulak, atomoak, ioiak eta elektroiak. Gelaxka zeharkatzen duen gas inerte batek (He edo Ar) ICPMS-ra garraiatzen ditu partikulak eta, bertan, aerosol hori lurrundu, atomizatu eta ionizatu egiten da eta sortutako ioi positiboak masa-espektrometroan analizatzen dira (3. irudia) [31].

Ikerketa honetan, tiro egin ondoren eskuan atxikita geratzen diren tiroaztarnen lagin-biltzea tape-lifting teknikaren bitartez egitea proposatzen da, hau da, karbonozko zinta erabiliz. Ondoren, laser bidezko ablazioko gelaxkan sartu eta laserrak zintaren gainazalean eragiten du. Laserraren diametroa $160 \mu \mathrm{m}$-koa da eta eta $20 \mu \mathrm{m} \mathrm{s}^{-1}$ translazio-abiadurarekin modu jarraian desplazatzen da 66 minutu irauten duen sigi-saga erako (raster) patroi bat jarraituz (4. irudia). Nahiz eta partikulen tamaina estimatzea ezinezkoa izan, erreferentziazko material baten garapenak partikulen tamaina ezagutzea ahalbidetuko luke, haien dentsitatea ezaguna baita [31]. Hala ere, munizio berrien garapenarekin, GSR partikulen tamaina eta morfologia eztabaidan jarri da eta ezin dira parametro baztertzailetzat hartu $[10,15]$.

Lortzen den erregistroa kromatograma baten oso antzekoa da, detektatzen diren elementuen seinalearen intentsitatea denborarekiko irudikatzen baita. Horrela, laserrak su-arma bat tirokatzean sortzen den partikula bat aurkitzen badu, ENFSIk ezarritako irizpideari jarraituz, $\mathrm{Pb}-\mathrm{ak}$, Sb-ak eta Ba-ak seinalea eman beharko lukete aldi berean, 3. irudian adierazten den bezala. 
Nora Unceta, Nagore Grijalba, Sandra Benito, Zuriñe Abrego, Alicia Sánchez, M. Aránzazu Goicolea, Alberto Gomez, Asier Vallejo, Ramón J. Barrio

A)

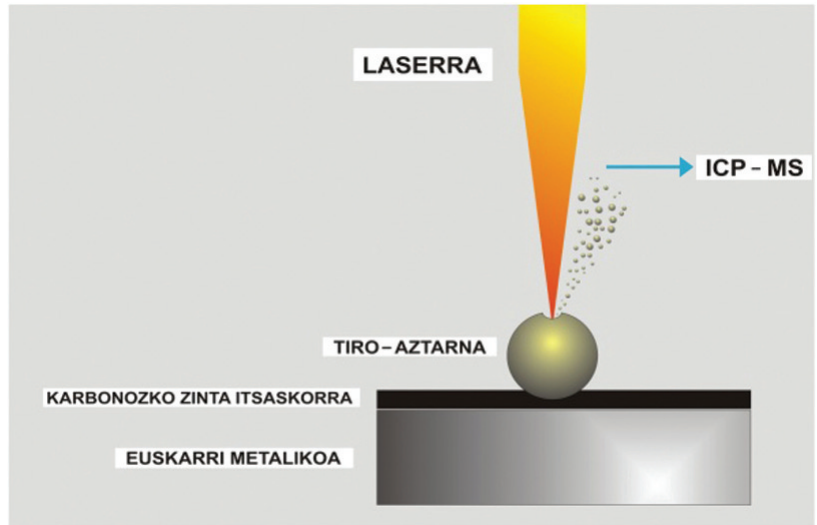

B)
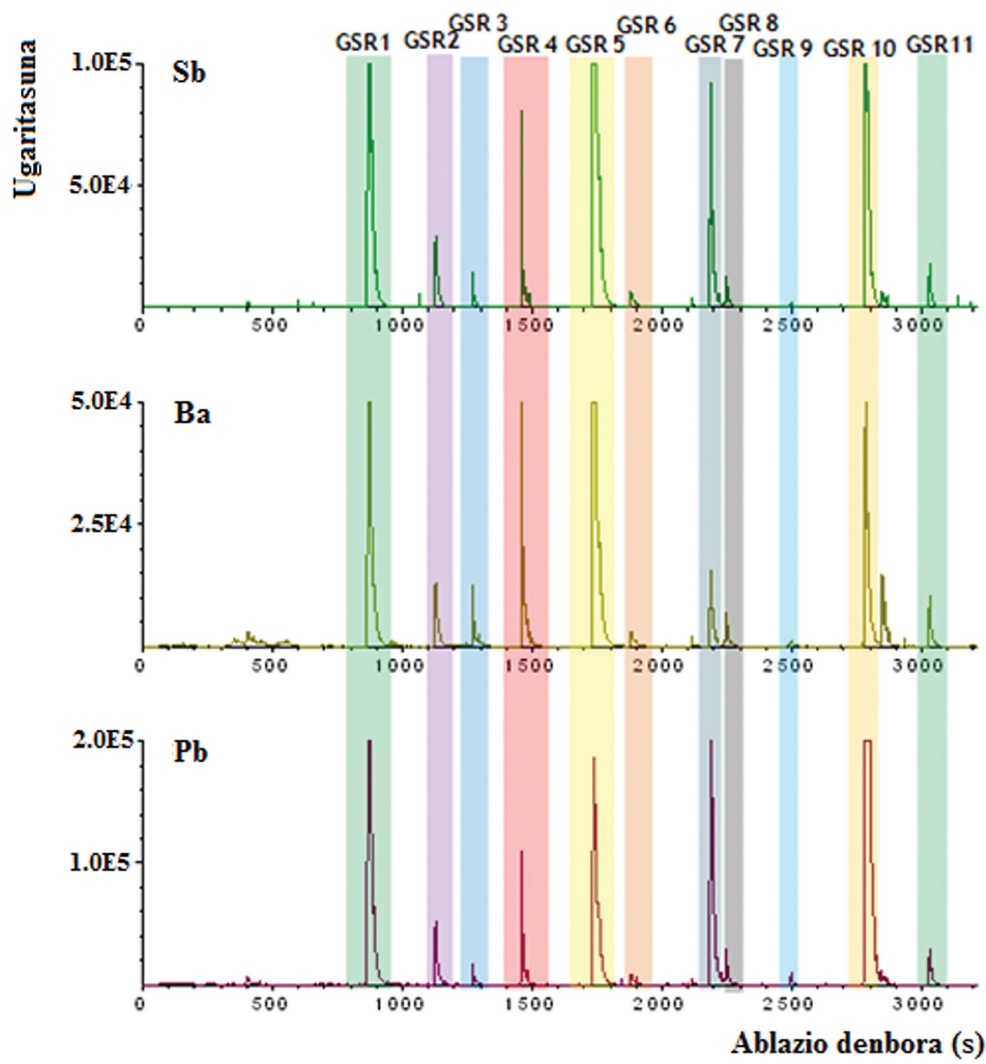

3. irudia. A) Laserrak partikularen gain eragin, materia erauzi eta gas inerte batek ICPMS-ra garraiatzen ditu. B) ICPMS detektagailuan $\mathrm{Sb}, \mathrm{Ba}$ eta $\mathrm{Pb}$ elementuen seinaleek denboran bat egiten dutenean partikula tiro-aztarna bati dagokiola baieztatu daiteke. Irudian 11 tiro-aztarna (GSR) bereiz daitezke. 


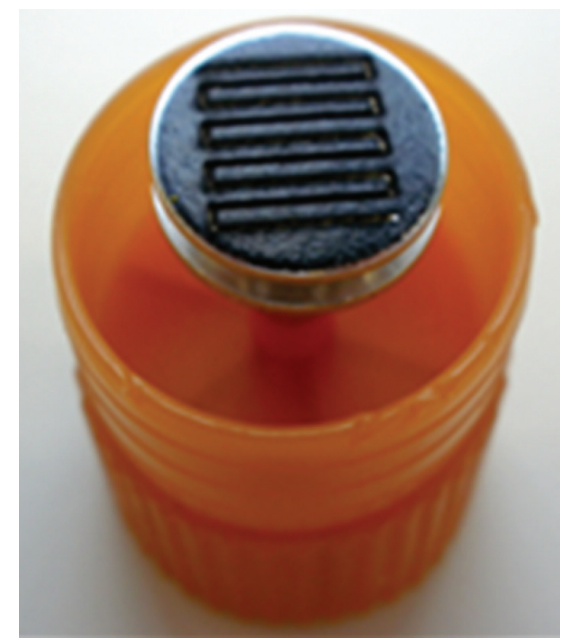

4. irudia. Laserrak karbonozko zinta itsasgarrian sortutako sigi-saga erako patroia.

LA-ICPMS teknikan oinarritzen den metodologia hau ohikoak diren zenbait munizioren tiroketaren ostean eskuetan atxikitzen diren partikulen analisian erabili da. Lagin guztietan $\mathrm{Pb}-\mathrm{Sb}-\mathrm{Ba}$ konposizioa duten partikulak aurkitu dira, eta partikula kopurua SEM-EDX bidez analizatu ostean lortutakoarekin bat dator [31]. Hortaz, LA-ICPMS teknika SEM-EDX teknikaren ordezko aukera azkarra dela baieztatu daiteke.

Behin laser bidezko metodoaren baliagarritasuna frogatuta, lau munizio berde desberdinen tiro-aztarnak analizatu dira, beruna ez duten hiru munizio eta metal astunik ez duen munizio bat [32]. Argitu beharra dago, munizio hauek beruna edo metal astunak ez dituztela esaten denean, metal astunak hasarazletik kendu direla esan nahi dela, eta askotan bala edota kartutxoetan metal astunak aurkitu daitezke. ENFSIk bereizgarritzat jotzen dituen $\mathrm{Pb}$-Sb-Ba partikulak laser bidezko ablazioaren bidez analizatu diren munizio guztietan identifikatu badira ere, haien kopurua eta intentsitatea aldakorra da munizioak duen berun edota metal astunen kantitatearen arabera. Arrazoi nagusia su-armak duen memoria efektua izan daiteke, aurretik beruna duen munizio batekin tiro egin ondoren tiro-aztarnak bertan denbora luzez geratzen baitira $[27,33]$. Halere, hasarazlean berunik ez duten munizioetan, berunaren seinalearen intentsitatea txikiagoa da beruna duten munizioekin konparatuz, eta are txikiagoa metal astunik ez duten munizioetan. Barioaren eta antimonioaren kasuan, murrizketa hori metal astunik ez duten munizioetan da nabaria. Honek guztiak $\mathrm{Pb}-\mathrm{Ba}-\mathrm{Sb}$ partikulen jatorria beste bat ere izan daitekeela adierazten du. Berunik ez duten hasarazlea eduki arren berunezko bala duten munizioetan, berun-jatorria bala bera 
Nora Unceta, Nagore Grijalba, Sandra Benito, Zuriñe Abrego, Alicia Sánchez, M. Aránzazu Goicolea, Alberto Gomez, Asier Vallejo, Ramón J. Barrio

izan daiteke. Metal astunik ez duten munizioetan, aldiz, balak su-armatik ateratzerakoan kanoian eragiten duen frikzioaren ondorioz aska daitezke partikula hauek. Partikula bereizgarri horiez gain, munizio berde hauetan bestelako konposizioa duten partikula batzuk ere aurkitu dira, Sb-Ba, $\mathrm{Cu}-\mathrm{Zn}, \mathrm{Al}-\mathrm{Ti}$ eta $\mathrm{Al}-\mathrm{Sr}-\mathrm{Zr}$, besteak beste. Halere, ezinezkoa da munizio berezi hauetan bereizgarria den partikula mota bat definitzea, eta munizio bakoitza kasuz kasu analizatuz, partikulen konposizio bereizgarri bat definitu beharko litzateke [32].

Ondorioz, kontuan izanik ENFSIk beruna duten munizioentzat ezartzen duen irizpidea zalantzan jarri dela, eta munizio berdeen partikulen identifikazioa ezinezkoa dela, beharrezkoa da tiro-aztarnen presentzia egiaztatzen duen ebidentzia osagarria eta, hortaz, ezinbestekoa bihurtzen da konposatu organikoen analisia.

\subsection{Tiro-aztarna organikoen analisia}

Partikula ez-organikoen analisira bideratu diren metodo analitikoak aspalditik erabili badira ere, azken urteotan nabarmen hazi da tiro-aztarna organikoen analisia helburu duten metodoen garapena, batez ere 1997. urtean Meng-ek eta Caddy-k argitaratu zuten errebisio bibliografikoaz geroztik [3].

Tiro-aztarna organikoen analisia nahiko ikertu bada ere, gutxi dira aztarna hauek eskuetan detektatzeko eta identifikatzeko aukera ematen duten metodoak. Lagin-biltzea egitean aurkitu daitezkeen partikula organikoen kantitatea oso txikia denez, sentsibilitate handia izan behar du teknika analitikoak. Erabili diren teknikak bi multzo nagusitan sailka daitezke: espektroskopikoak eta kromatografikoak.

Espektroskopia infragorria teknikaren oinarria molekula batek erradiazio infragorria xurgatzean jasaten duen bibrazio-energiaren aldaketa da. Teknika hau batez ere tiro egin duen pertsonaren eta jomugaren artean dagoen distantzia ezagutzeko [34,35], balaren sarrerako zuloa identifikatzeko [35] eta munizio eta tiro-aztarnen karakterizaziorako erabili izan da (5. irudia) [36,37].

Raman espektroskopian ere erradiazio infragorria xurgatzen du molekulak, baina kasu honetan erradiazioaren dispertsioa da neurtzen dena. Hasiera batean Raman espektroskopia tiro-aztarnetako konposatu ez-organikoen identifikaziorako erabili zen, berun eta bario gatzen identifikaziorako hain zuzen ere [38]. Azkeneko urteotan, teknika horrek konposatu organikoen identifikazioa ahalbidetu du [39]. Metodologia estatistikoekin batera, espektroskopia hau munizioaren kalibrea ezagutzeko ere erabili da [40]. Tamalez, ikerketa horietan beharrezkoa da munizio bakoitza banan-banan analizatzea, baina bideraezina da hori. Berriki, Abrego eta lankideek partikula ez-organiko eta organikoak analizatzeko LA-ICPMS eta Raman es- 

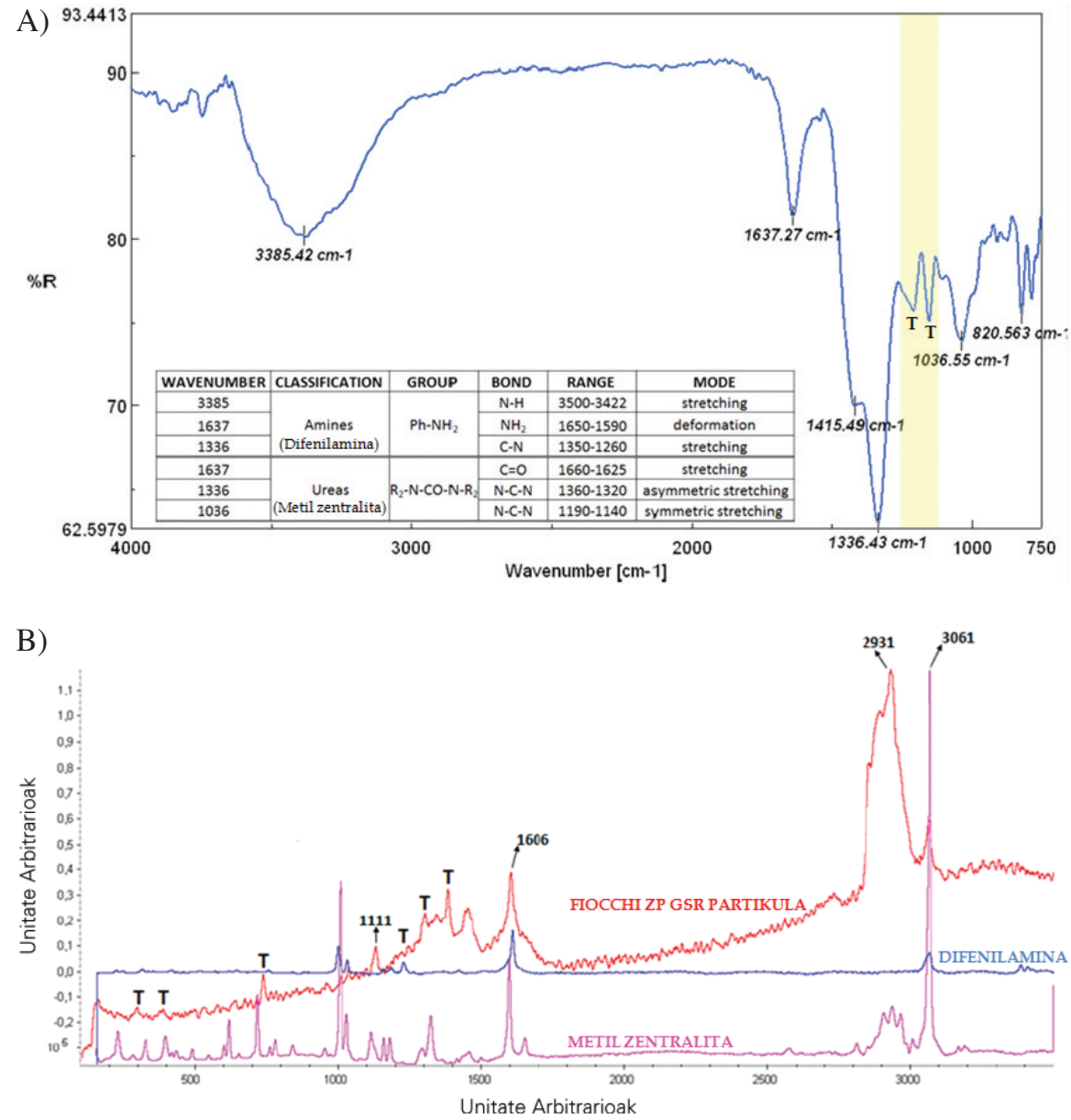

5. irudia. «Metal astunik gabeko» Fiocchi $9 \mathrm{~mm}$ Luger ZP munizioaren tiroaztarnen infragorri (A) eta Raman (B) espektroak. Bietan difenilaminari eta zentralitei dagozkien bandak aurkitzen dira («T» letrarekin PTFEari dagozkion bandak adierazten dira).

pektroskopia konbinatzen dituen metodo analitikoa garatu dute eta munizio berdeek sortutako partikulak analizatu dituzte [32]. Helburu horrekin, lagin-biltzea egiteko erabiltzen den karbonozko zinta itsaskorra estali egiten da, neurri batean, lehenengo parafilm-ezko xafla batekin, eta ondoren PTFEzko (politetrafluoroetileno) batekin (6. irudia). Horrela, LA-ICPMS bidez egiten da karbonozko zintan itsatsita gelditu diren partikula ez-organikoen identifikazioa. PTFE xaflan, aldiz, tiro-aztarna organikoak Raman espektroskopia bidez analizatzen dira. Azken teknika horrekin, identifikatu 
Nora Unceta, Nagore Grijalba, Sandra Benito, Zuriñe Abrego, Alicia Sánchez, M. Aránzazu Goicolea, Alberto Gomez, Asier Vallejo, Ramón J. Barrio

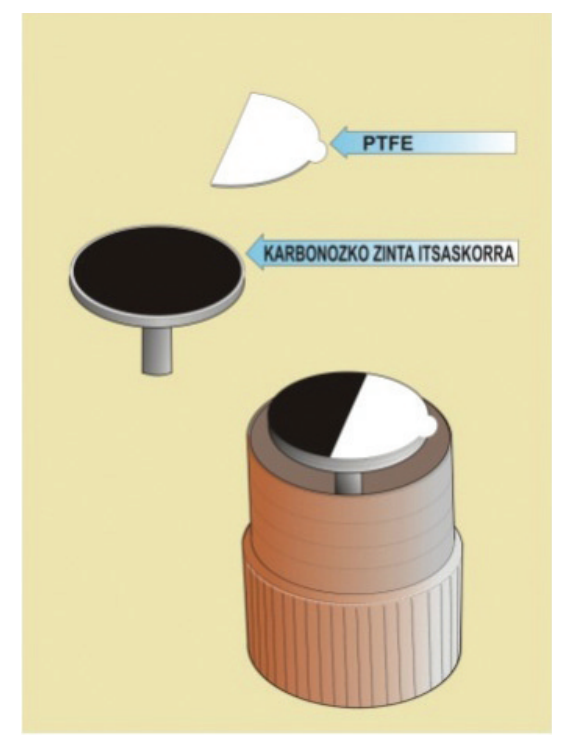

6. irudia. PTFE xafla batekin aldatutako karbonozko zinta itsaskorra.

egin dira tiro-aztarnen ezaugarri diren zentralitak eta difenilaminen deribatu nitratuak, eta horrek informazio gehigarri baliotsua ematen dio partikula ez-organikoen ebidentziari.

Partikula organikoen analisira bideratutako teknika kromatografikoak hainbat detektagailutara akoplatu izan dira. Esate baterako, gas-kromatografiaren kasuan, energia termikoaren detektagailuarekin (TEA) [41], elektroi harrapaketaren detektagailuarekin (ECD) [42] eta masa-espektrometriarekin (MS) $[43,44]$ batera erabili dira. Halere, gas-kromatografian erabiltzen diren tenperatura altuek nitroglizerinaren eta nitrosodifenilaminen degradazioa eragiten dute $[3,27,45]$. Hori dela eta, gomendagarriagoa da likido-kromatografia erabiltzea, eta, aukeran, masa-espektrometro bati akoplatuta, hura baita konposatuen identifikazioaren fidagarritasuna ziurtatzen duen detektagailu bakarra.

Konposatu organikoen analisia egiteko masa-espektrometrian oinarritzen diren metodo ezberdinak garatu diren arren [2,3], batez ere bolborak eta bolboren lehergaiak analizatzeko erabili dira. Haien artetik likido-kromatografiari lotutako hegaldi-denbora masa-espektrometria ( $L C-T O F, l i-$ quid chromatography coupled to time of flight mass spectrometry) aipatu beharra dago. Hegaldi-denbora erako analizatzaileak erresoluzio askoz handiagoa du gainerako masa analizatzaileen aldean, eta, horri esker, konposatuen masa zehatza zehaztea ahalbidetzen du. Hori dela eta, teknika hau 
Tiro-aztarnen identifikazioa, auzitegi-laborategien erronka

oso erabilgarria da, bai analisi kuantitatiboak egiteko, bai eta, batez ere, kualitatiboak egiteko.

Teknika horretan konposatuen arteko bereizketa egiteko likido-kromatografia erabiltzen denez, derrigorrezkoa da lagina disolbatuta edukitzea. Horretarako, Raman espektroskopian ez bezala, beharrezkoa da laginaren tratamendua. Benito eta lankideek aurten argitaratu duten lanean ere, PTFE xaflaz estalitako karbonozko zinta erabiltzen da eta bertan jasotako tiro-aztarnak metanolarekin erauzten dira [46]. Analisia LC-QTOF (liquid chromatography coupled to quadrupole-time of flight mass spectrometry) bidez egitean, aztertu diren munizio guztietan zentralitak eta difenilaminaren deribatuak aurkitu dira, besteak beste (7. irudia). Jakina, teknika hau laser bidezko ablazioarekin batera erabili daiteke munizioek oro har eta, batez ere, munizio berdeek igortzen dituzten tiro-aztarnen identifikazioa posible egiteko.

\section{ONDORIOAK}

Ondorio gisa, esan daiteke azkenaldi honetan elkarren osagarriak diren metodo analitiko ugari garatu direla delituzko ekintzak eta suizidioak argitzeko. Halako metodoen helburutzat eman daiteke, era berean, munizioetan agertzen diren konposatu ez-organikoak eta organikoak identifikatzea, bai eta, zenbait kasutan, kuantifikatzea.

Hala ere, horietako zenbait teknikak berebiziko garrantzia dute eskaintzen dituzten abantailei esker. Tiro-aztarna ez-organikoei dagokienez, berriki garatu den LA-ICPMS-ean oinarritutako metodo analitikoak laginak ordu batean analizatzea ahalbidetzen du eta, gainera, partikula bakoitzaren informazioa eskaintzen du. Horregatik, erreferentziazko teknika izan daiteke luzarora, gaur egun den SEM-EDX teknika ordezkatuz.

Bestalde, tiro-aztarna organikoen analisiek ohituraz analizatu diren eta gaur egun balio judiziala duten tiro-aztarna ez-organikoen froga-balioa indartzen dute, batez ere geroz eta erabilera zabalagoa duten munizio berdeen kasuan.

\section{ESKER ONAK}

Egileek Eusko Jaurlaritzako Hezkuntza, Hizkuntza Politika eta Kultura Sailari eskertzen diote Euskal Unibertsitate Sistemako ikerketataldeen jarduera bultzatzeko diru-laguntza (IT338-10 proiektua). Sandra Benito ikerlariak Hezkuntza, Hizkuntza Politika eta Kultura Sail berak doktorego-tesia sustatzeko emandako diru-laguntza eskertzen du. Nagore Grijalbak Université de Pau et Des Pays de L'Adour-i (UPPA) 
Nora Unceta, Nagore Grijalba, Sandra Benito, Zuriñe Abrego, Alicia Sánchez, M. Aránzazu Goicolea, Alberto Gomez, Asier Vallejo, Ramón J. Barrio

A)
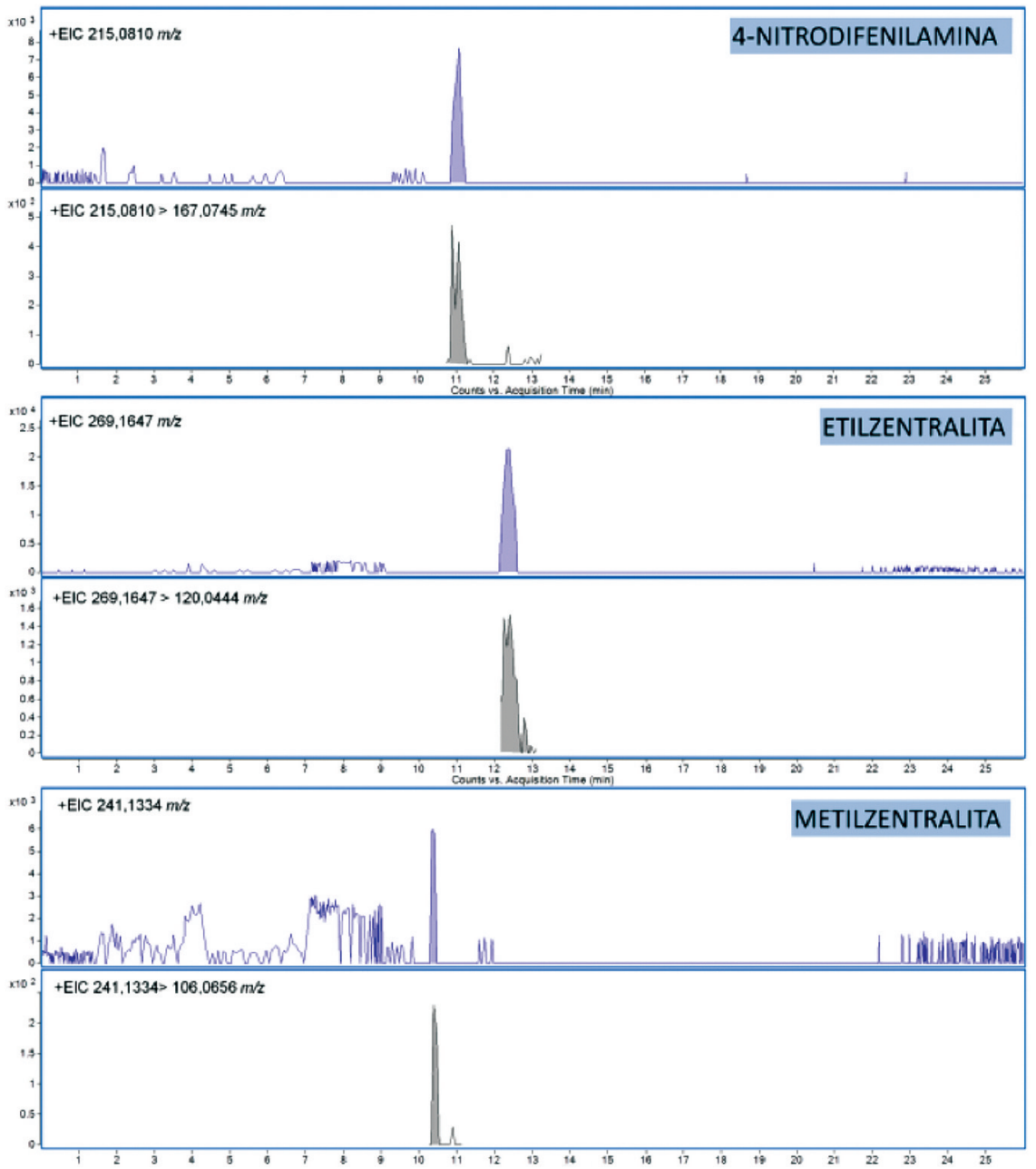

7. irudia. «Berunik gabeko» Remington/UMC Leadless TM 9 mm Luger munizioaren tiro-aztarnen analisia LC-QTOF bidez. 4-nitrodifenilamina, etilzentralita eta metilzentralitaren MS eta MS/MS kromatogramak (A) eta espektroak (B). 
B)
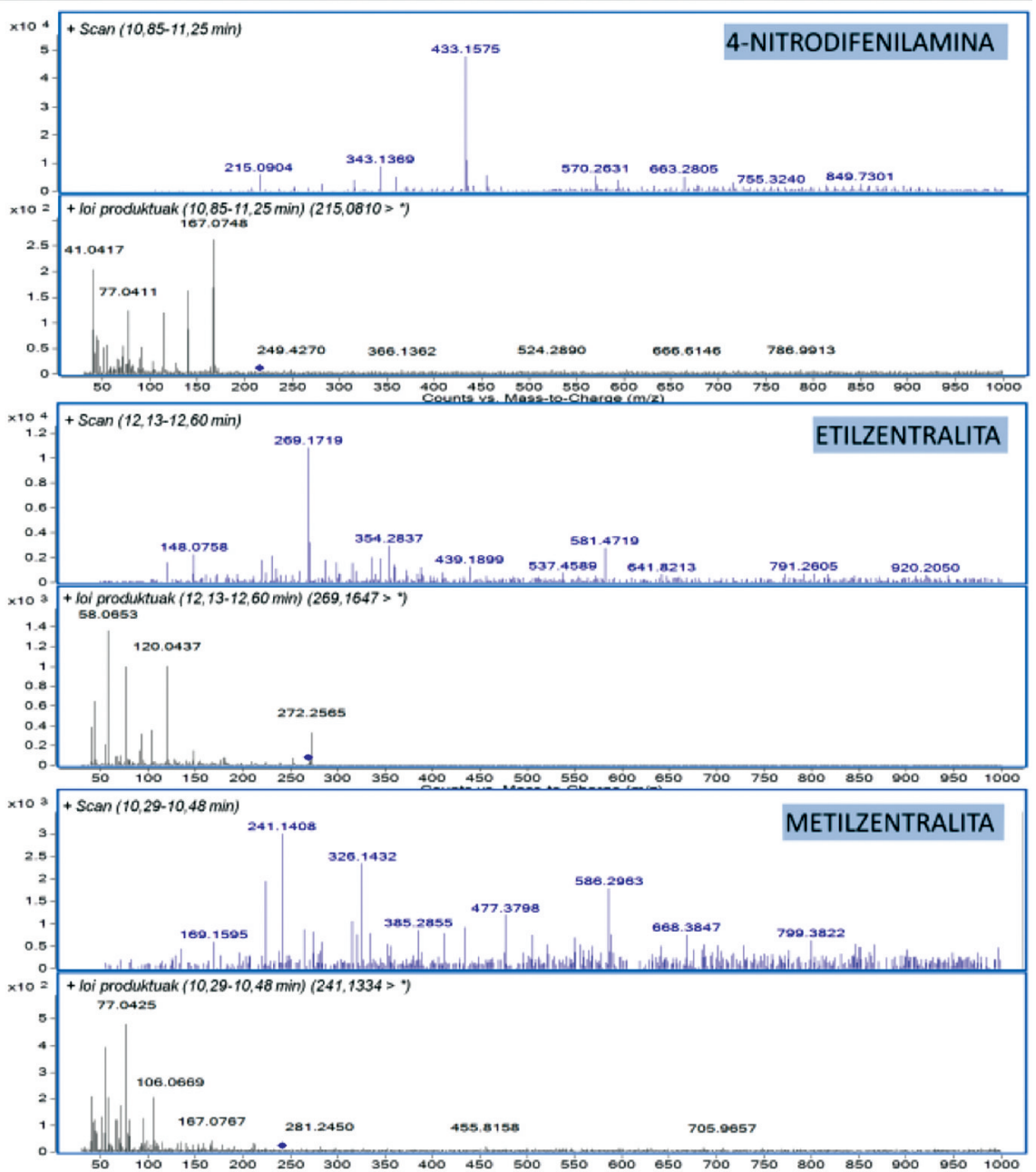

7. irudia. (jarraitu) 
Nora Unceta, Nagore Grijalba, Sandra Benito, Zuriñe Abrego, Alicia Sánchez, M. Aránzazu Goicolea, Alberto Gomez, Asier Vallejo, Ramón J. Barrio

eta Euskal Herriko Unibertsitateari (UPV/EHU) eskertzen die tutorekidetza erregimenean doktorego tesia egiteko diru-laguntza. Era berean, egile guztiek Euskal Herriko Unibertsitateko Arabako Analisirako Zerbitzu Zentralak, Multiespektroskopia Akoplatuen Laborategi Bereziak (RamanMAKLAB) eta Polizia eta Larrialdietako Euskal Akademiak eskainitako laguntza teknikoa eskertu nahi dute.

\section{BIBLIOGRAFIA}

[1] ROMOLO, F.S. eta MARGOT, P. 2001. «Identification of gunshot residue: a critical review». Forensic Science International, 119, 195-211.

[2] DALBY, O.; BUTLER, D. eta BIRKETT JASON, W. 2010. «Analysis of gunshot residue and associated materials. A review». Journal of Forensic Sciences, 55, 924-943.

[3] MENG, H.-H. eta CADDY, B. 1997. «Gunshot residue analysis. A review». Journal of Forensic Sciences, 42, 553-570.

[4] BASU, S. 1982. «Formation of gunshot residues». Journal of Forensic Sciences, 27, 72-91.

[5] WOLTEN, G.M. eta NESBITT, R.S. 1980. «On the mechanism of gunshot residue particle formation». Journal of Forensic Sciences, 25, 533-545.

[6] HEARD, B.J. 2008. Handbook of Firearms and Ballistics. John Wiley \& Sons, Ltd., Chichester (UK).

[7] SCHWOEBLE, A.J. eta EXLINE, D. 2000. Current Methods in Forensic Gunshot Residue Analysis. CRC Publisher, Boca Ratón (Florida).

[8] NIEWOEHNER, L. 2008. ENFSI-Guide for gunshot residue analysis by scanning electron microscopy/energy-dispersive X-ray spectrometry. ENFSI, Prague.

[9] ASTM. 2010. Standard Guide for Gunshot residue Analysis by Scanning Electron Microscopy/Energy Dispersive X-Ray Spectrometry. ASTM international, Subcommittee E30.01 on Criminalistics, West Conshohocken (PA).

[10] MARTINY, A.; CAMPOS ANDREA, P.C.; SADER MARCIA, S. eta PINTO ANDRE, L. 2008. «SEM/EDS analysis and characterization of gunshot residues from Brazilian lead-free ammunition». Forensic Science International, 177, e9-17.

[11] CARDINETTI, B.; CIAMPINI, C.; D'ONOFRIO, C.; ORLANDO, G.; GRAVINA, L.; FERRARI, F.; DI TULLIO, D. eta TORRESI, L. 2004. «Xray mapping technique: a preliminary study in discriminating gunshot residue particles from aggregates of environmental occupational origin». Forensic Science International, 143, 27-46.

[12] MOSHER, P.V.; MCVICAR, M.J.; RANDALL, E.D. eta SILD, E.H. 1998. «Gunshot residue-similar particles produced by fireworks». Canadian Society of Forensic Science Journal, 31, 157-168. 
Tiro-aztarnen identifikazioa, auzitegi-laborategien erronka

[13] CHARPENTIER B. eta DESROCHERS C. 2000. «Analysis of primer residue from lead-free ammunition by x-ray microfluorescence». Journal of Forensic Sciences, $\mathbf{4 5}, 447-452$.

[14] MOXNES, J.F.; JENSEN, T.L.; SMESTAD, E.; UNNEBERG, E. eta DULLUM, O. 2013. «Lead Free Ammunition without Toxic Propellant Gases». Propellants, Explosives, Pyrotechnics, 38, 255-260.

[15] OOMMEN, Z. eta PIERCE, S.M. 2006. «Lead-free primer residues: A qualitative characterization of Winchester WinClean Remington/UMC LeadLess, Federal BallistiClean and Speer Lawman CleanFire handgun Ammunition». Journal of Forensic Sciences, 51, 509-519.

[16] ZEICHNER, A. 2001. «Is there a real danger of concealing gunshot residue (GSR) particles by skin debris using the tape-lift method for sampling GSR from hands?» Journal of Forensic Sciences, 46, 1447-1455.

[17] DEGAETANO, D.; SIEGEL, J.A. eta KLOMPARENS, K.L. 1992. «A comparison of three techniques developed for sampling and analysis of gunshot residue by scanning electron microscopy/energy-dispersive $\mathrm{x}$-ray analysis (SEM-EDX)». Journal of Forensic Sciences, 37, 281-300.

[18] ZEICHNER, A. eta LEVIN, N. 1993. «Collection Efficiency of Gunshot Residues (GSR) particles from hair and hands using double-side adhesive tape». Journal of Forensic Sciences, 38, 571-584.

[19] WALLACE, J.S. eta MCKEOWN, W. 1993. «Sampling procedures for firearms and/or explosives residues». Journal of the Forensic Science Society, 33, 107-116.

[20] CAPANNESI, G. eta SEDDA, A.F. 1992. «Bullet identification: a case of a fatal hunting accident resolved by comparison of lead shot using instrumental neutron activation analysis». Journal of Forensic Sciences, 9, 657-662.

[21] GAGLIANO-CANDELA, R.; COLUCCI, A.P. eta NAPOLI, S. 2008. «Determination of firing distance. Lead analysis on the target by atomic absorption spectroscopy (AAS)». Journal of Forensic Sciences, 53, 321-324.

[22] NEWTON, J.T. 1981. «Rapid determination of antimony, barium, and lead in gunshot residue via automated atomic absorption spectrophotometry». Journal of Forensic Sciences, 26, 302-312.

[23] LOPER, G.L.; CALLOWAY, A.R.; STAMPS, M.A.; WOLTEN, G.M. eta JONES, P.F. 1981. «Use of photoluminescence to investigate apparent suicides by firearms». Journal of Forensic Sciences, 26, 263-287.

[24] NESBITT, R.S.; WESSEL, J.E.; WOLTEN, G.M. eta JONES, P.F. 1977. «Evaluation of a photoluminescence technique for the detection of gunshot residue». Journal of Forensic Sciences, 22, 288-303.

[25] KOONS, R.D.; HAVEKOST, D.G. eta PETERS, C.A. 1988. «Determination of barium in gunshot residue collection swabs using inductively coupled plasmaatomic emission spectrometry». Journal of Forensic Sciences, 33, 35-41.

[26] UDEY, R.N.; HUNTER, B.C. eta SMITH, R.W. 2011. «Differentiation of bullet type based on the analysis of gunshot residue using inductively coupled plasma mass spectrometry». Journal of Forensic Sciences, 56, 1268-1276. 
Nora Unceta, Nagore Grijalba, Sandra Benito, Zuriñe Abrego, Alicia Sánchez, M. Aránzazu Goicolea, Alberto Gomez, Asier Vallejo, Ramón J. Barrio

[27] ZEICHNER, A.; EHRLICH, S.; SHOSHANI, E. eta HALICZ, L. 2006. «Application of lead isotope analysis in shooting incident investigations». Forensic Science International, 158, 52-64.

[28] WOLTEN, G.M.; NESBITT, R.S.; CALLOWAY, A.R.; LOPER, G.L. eta JONES, P.F. 1979. «Particle analysis for the detection of gunshot residue. I: Scanning electron microscopy/energy dispersive x-ray characterization of hand deposits from firing». Journal of Forensic Sciences, 24, 409-422.

[29] ERDEN, S.; DURMUS, Z. eta KILIC, E. 2011. «Simultaneous Determination of Antimony and Lead in Gunshot Residue by Cathodic Adsorptive Stripping Voltammetric Methods». Electroanalysis, 23, 1967-1974.

[30] ZEICHNER, A. 2003. «Recent developments in methods of chemical analysis in investigations of firearm-related events». Analytical and Bioanalytical Chemistry, 376, 1178-1191.

[31] ABREGO, Z.; UGARTE, A.; UNCETA, N.; FERNANDEZ-ISLA, A.; GOICOLEA, M.A. eta BARRIO, R.J. 2012. «Unambiguous Characterization of Gunshot Residue Particles Using Scanning Laser Ablation and Inductively Coupled Plasma-Mass Spectrometry». Analytical Chemistry, 84, 2402-2409.

[32] ABREgO, Z.; GRIJALBA, N.; UNCETA, N.; MAGUREGUI, M.; SANCHEZ, A.; FERNANDEZ-ISLA, A.; GOICOLEA, M.A. eta BARRIO, R.J. 2014. «A novel method for the identification of inorganic and organic gunshot residue particles of lead-free ammunitions from the hands of shooters using scanning laser ablation-ICPMS and Raman micro-spectroscopy». Analyst, 139, 6232-6241.

[33] HARRIS, A. 1995. «Analysis of primer residue from CCI Blazer lead free ammunition by scanning electron microscopy/energy dispersive $\mathrm{x}$-ray». Journal of Forensic Sciences, 40, 27-30.

[34] MOU, Y.; LAKADWAR, J. eta RABALAIS, J.W. 2008. «Evaluation of shooting distance by AFM and FTIR/ATR analysis of GSR». Journal of Forensic Sciences, 53, 1381-1386.

[35] SHARMA, S.P. eta LAHIRI, S.C. 2009. «A preliminary investigation into the use of FTIR microscopy as a probe for the identification of bullet entrance holes and the distance of firing». Science \& Justice, 49, 197-204.

[36] BUENO, J.; SIKIRZHYTSKI, V. eta LEDNEV, I.K. 2013. «Attenuated Total Reflectance-FT-IR Spectroscopy for Gunshot Residue Analysis: Potential for Ammunition Determination». Analytical Chemistry, 85, 7287-7294.

[37] ABREGO, Z. 2014. Characterization of Gunshot Residues by Surface Analysis Techniques. Euskal Herriko Unibertsitatea (UPV/EHU), Vitoria-Gasteiz.

[38] STICH, S.; BARD, D.; GROS, L.; WENZ, H.W.; YARWOOD, J. eta WILLIAMS, K. 1998. «Raman microscopic identification of gunshot residues». Journal of Raman Spectroscopy, 29, 787-790.

[39] LOPEZ-LOPEZ, M.; DELGADO, J.J. eta GARCIA-RUIZ, C. 2012. «Ammunition Identification by Means of the Organic Analysis of Gunshot Residues Using Raman Spectroscopy». Analytical Chemistry, 84, 3581-3585. 
Tiro-aztarnen identifikazioa, auzitegi-laborategien erronka

[40] BUENO, J.; SIKIRZHYTSKI, V. eta LEDNEV, I.K. 2012. «Raman Spectroscopic Analysis of Gunshot Residue Offering Great Potential for Caliber Differentiation». Analytical Chemistry, 84, 4334-4339.

[41] MULLER, D.; LEVY, A.; VINOKUROV, A.; RAVREBY, M.; SHELEF, R.; WOLF, E.; ELDAR, B. eta GLATTSTEIN, B. 2007. «A novel method for the analysis of discharged smokeless powder residues». Journal of Forensic Sciences, 52, 75-78.

[42] DOUSE, J.M.F. eta SMITH, R.N. 1986. «Trace analysis of explosives and firearm discharge residues in the metropolitan police forensic science laboratory». Journal of Energetic Materials, 4, 169-186.

[43] DALBY, O. eta BIRKETT, J.W. 2010. «The evaluation of solid phase micro-extraction fibre types for the analysis of organic components in unburned propellant powders». Journal of Chromatography, A, 1217, 7183-7188.

[44] ZEICHNER, A.; ELDAR, B .; GLATTSTEIN, B.; KOFFMAN, A.; TAMIRI, T. eta MULLER, D. 2003. «Vacuum collection of gunpowder residues from clothing worn by shooting suspects, and their analysis by GC/TEA, IMS, and GC/MS». Journal of Forensic Sciences, 48, 961-972.

[45] ESPINOZA, E.O.N. eta THORNTON, J.I. 1994. "Characterization of smokeless gunpowder by means of diphenylamine stabilizer and its nitrated derivatives». Analytica Chimica Acta, 288, 57-69.

[46] BENITO, S.; ABREGO, Z.; SANCHEZ, A.; UNCETA, N.; GOICOLEA, M.A. eta BARRIO, R.J. 2015. «Characterization of organic gunshot residues in lead-free ammunition using a new sample collection device for liquid chromatography-quadrupole time-of-flight mass spectrometry». Forensic Science International, 246, 79-85. 